\title{
How the Regular Teaching Converted to Fully Online Teaching in Saudi Arabia during the Coronavirus COVID-19
}

\author{
Yasser Ali Alshehri, Najwa Mordhah, Sameer Alsibiani, Samir Alsobhi, Noha Alnazzawi \\ Yanbu University College, Royal Commission at Yanbu, Yanbu Al Sinaiyah, Saudi Arabia \\ Email: alshehriya@rcyci.edu.sa, mordhahn@rcyci.edu.sa, alsibiani@rcyci.edu.sa, alsobhis@rcyci.edu.sa, \\ alnazzawin@rcyci.edu.sa
}

How to cite this paper: Alshehri, Y. A., Mordhah, N., Alsibiani, S., Alsobhi, S., \& Alnazzawi, N. (2020). How the Regular Teaching Converted to Fully Online Teaching in Saudi Arabia during the Coronavirus COVID-19. Creative Education, 11, 985-996. https://doi.org/10.4236/ce.2020.117071

Received: June 4, 2020

Accepted: July 10, 2020

Published: July 13, 2020

Copyright $\odot 2020$ by author(s) and Scientific Research Publishing Inc. This work is licensed under the Creative Commons Attribution International License (CC BY 4.0).

http://creativecommons.org/licenses/by/4.0/

\begin{abstract}
During the Coronavirus COVID19 crisis, most of the affected countries forced the stay-home policy, which causes workers from many sectors to continue their work from home. Schools, colleges, and universities are conducting teaching activities through the internet. The online education used for many years to support the regular education. However, in this crisis, educational institutions are switched into $100 \%$ online teaching. There are many challenges associated with this transition, which makes us rethink about prioritizing education spending and put online education upfront. Also, it is time to rewrite the risk policies and consider biological threats as one of the possible risks that obstruct regular education. In this study, we highlighted the experience of a mid-size college in Saudi Arabia with this circumstance. We evaluated this experience from its beginning to the end of the semester. We summarized many lessons learned from this experience how to mitigate the effect associated with the crisis.
\end{abstract}

\section{Keywords}

Online Education, Remote Emergency Teaching, Biological Crisis and Education, Coronavirus COVID19 and Education, Case Study

\section{Introduction}

Except for the colleges offer $100 \%$ online degrees, most of the other colleges worldwide are using online teaching methods as a support tool for regular teaching. Learners are given the choice to select between regular and online education. However, on some occasions, learners may not have other options except online 
education. There are some circumstances when learners are pushed to the online option such as being in a war (Rajab, 2018), living in remote places (Chen \& Koricich, 2014), being a worker, and do not have time to attend regular classrooms (Bourne et al., 2005), and biological crisis. Some of these occasions are happening in the middle of a school semester, which causes a sudden transition from regular teaching to online methods. Almost all countries experienced this circumstance when the world was hit with the coronavirus started in November 2019, and the virus is still hitting the world as of the time of writing this paper (WHO, 2020). The coronavirus COVID19 that outbroke in Wuhan, China has caused death to several thousands of individuals worldwide (Hasan \& Hossain, 2020; Chen et al., 2020; Ali et al., 2020). Also, it caused considerable economic disruptions due to the fast spread of the virus worldwide (Hasan \& Hossain, 2020). All countries declared an emergency to control the spread of the virus and slow it down. Part of the emergency procedures is to shut down schools, closing shops down, force in-house quarantine. Eliminating physical interaction can help to reduce the number of people infected every day, which helps to gain more time to get a treatment that can fight the virus. Therefore, the world had no choice except to use what technology can offer to continue education.

This situation is defined by (Hodges et al., 2020) as an emergency remote teaching. The paper emphasized that there is a clear distinguishing between the e-learning model and its standards and of what is happening right now in continuing the learning experience during the closure of the educational institutions. The authors in (Hodges et al., 2020) believed that the two terms should not be confused since the current situation is a reaction to a temporary problem. Key differences between e-learning and emergency remote teaching are summarized in Table 1.

In Saudi Arabia, the first case diagnosed with Corona was in February 2020. The government suspended attending schools in March 2020. The Ministry of Education decided to continue with the distance education using all possible online platforms to continue the delivery of the education at levels. The country experienced a similar situation during the wartime (Rajab, 2018). This experience happened in a single city in Saudi Arabia and was for a short period. However, this time the problem is due to the health issue and across all the countries.

Table 1. Differences between e-learning and emergency remote teaching.

\begin{tabular}{lcc}
\hline \multicolumn{1}{c}{ Characteristic } & E-learning $\begin{array}{c}\text { Emergency } \\
\text { remote } \\
\text { teaching }\end{array}$ \\
\hline It has systematic model for planning and design. & Yes & No \\
Depends on comprehensive dimensions of all aspect of E-learning. & Yes & No \\
Depends on an integrated environment of interconnected factors. & Yes & No \\
Aims to create learning community. & Yes & No \\
Provide temporary online solution. & Yes
\end{tabular}


Education can still be delivered during a crisis (Nash, 2015). Online education has been evolved over many years with the development of modern applications and Internet speed (Al-Khalifa, 2009; Walabe, 2020). The form of online learning should consider the three major elements: Student-Content, Student-Student, and Educator-Student interactions (Anderson, 2008; Smith, 2020). However, this circumstance is unique as, in one night, teachers needed to conduct their lectures online. Besides posting course materials into the learning platforms (e.g., Blackboard), teachers need to use applications (e.g., Collaborate, Zoom, Google classrooms) to meet their students asynchronously. Furthermore, they need to meet at the same time that they used to meet in to avoid any disruptions to students' schedules. This circumstance has brought the online teaching from asynchronous format to the blended format, which is the mixture of both synchronous and asynchronous.

This situation is unique and happened so quickly, which we think is important to investigate the impacts caused by this crisis. The pandemic has led to severe global economic disruptions and it has also led to the cancellation of major events. Many researchers have already started to publish their studies about the economic and financial impacts of COVID-19. Shortly, we will see many research works tackle the impact of this circumstance on different areas such as economy, politics, sociology, and psychology. In this work, we analyzed the impact on education that this crisis has caused. Some related works in education (e.g., Archambault \& Borup, 2020; Bozkurt \& Sharma, 2020; Schrading et al., 2020; McCartin, 2020) started this approach.

In this paper, we present the experience of higher education institutes in Saudi Arabia during the time of Coronavirus and how the institutions, professors, and students reacted to the situation. We assess the transition from a regular meeting classroom into virtual classrooms and how smooth this transition was at a mid-sized institution in Saudi Arabia. We heard feedback from teachers on how they found this experience working and studying remotely, especially when delivering specialized courses in computer science and engineering, management science, interior design, and applied linguistics. Finally, we produce some lessons learned from this time concerning education and the necessity of the involvement of e-learning.

The rest of the paper is organized as follows. The case study is explained in Section 2. In the case study section, we present facts about the college where we conducted the study (in Section 2.1), analyze the situation before the crisis (in Section 2.2), during the crisis (in Section 2.3), and lessons learned from this crisis (in Section 2.4). In the end, the paper is concluded in Section 3.

\section{Case Study}

We built this case study based on a survey sent to all faculty members, observing students' comments on social media, and interviewing heads of all departments. In this case study, we present facts related to the college including the number of students on each program and the number of courses, and sections on every department in the college. Second, we present the situation in the college before 
the beginning of the crisis with respect to the coverage of the curriculum and the percentage of assessed marks. Third, we present how the college handled education during the crisis. Fourth, we present lessons learned from this crisis that may need to change the roadmap for the future of online teaching.

\subsection{Facts}

The case study in this paper is a mid-size college. It has more than 2500 male and female students. The college has four departments and nine programs as shown in Figure 1. The number of students (male and female) is presented in the size of the bars in Figure 1. As shown, the human resources program has the highest number of students, followed by computer engineering, applied linguistics, management information systems, computer science, and supply chain management. The varieties of the offered programs add an extra challenge to the transition from regular to online teaching. It is more difficult to switch to online teaching on engineering courses or courses that require hands-on training (e.g., dealing with hardware or physical components in computer engineering program) than courses deliver only theoretical concepts (Bourne et al., 2005). Computer science, math, and statistics are less complex than hardware training, but it still carries some difficulties like writing or solving equations and drawing charts.

In Figure 2, we present the total number of courses, sections, and weekly teaching hours on campus. This helps to understand the amount of work needed for the transitions from the regular to online teaching. The figure presents the numbers at the department level. The management science department offers five programs, computer science and engineering offer two programs. The number of courses in both management science and computer departments is high because they have more than one program (five in management science and two in the computer department). Also, the two departments are offered on two campuses (male and female), which means the presented numbers are the aggregated numbers of the two campuses.

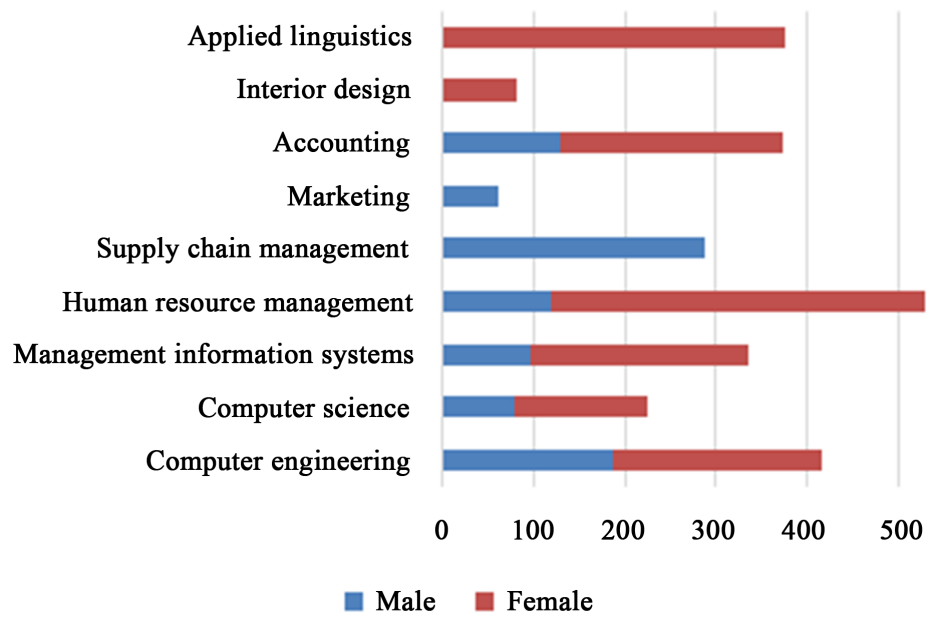

Figure 1. Programs and total number of students (male and female) in each program. 


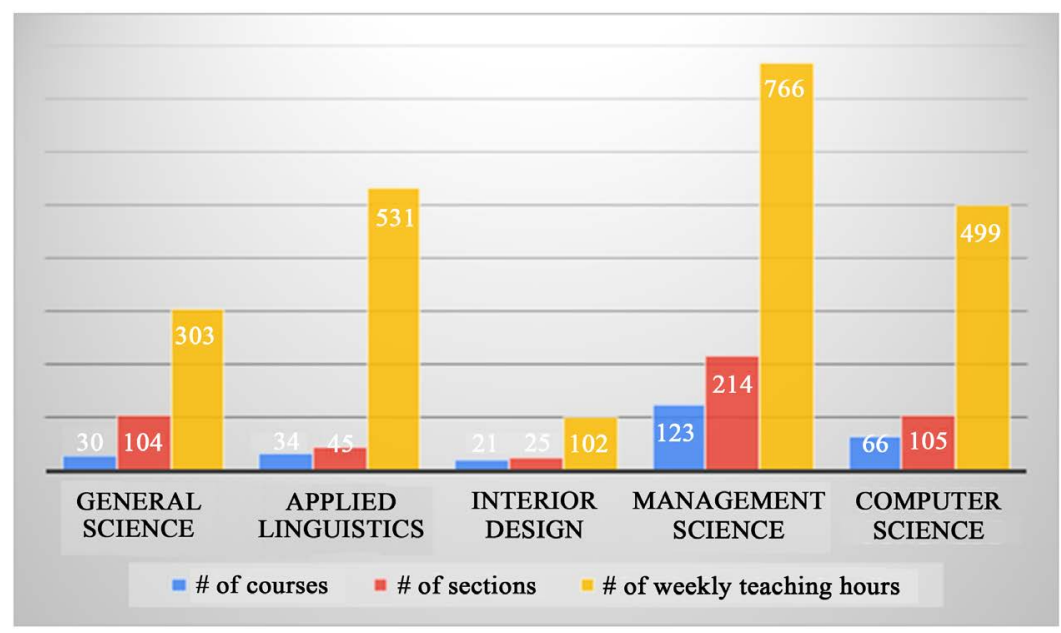

Figure 2. Number of courses, sections and weekly teaching hours.

\subsection{Before Crisis}

At the beginning of the crisis, we conducted a survey to analyze where we are before the crisis in terms of the curriculum delivery and the assessments for each course. We analyze the percentage of the syllabus of each course (i.e., including course level outcomes) delivered and what percentage of the syllabus was assessed before the crisis. Then, we analyzed how much of the remaining part was successfully delivered and assessed and how much of the remaining of the syllabus is planned to achieve. Besides, we highlight on methods used for communicating with students, delivering curriculum, and assessment methods used for the remaining part of the syllabus. Furthermore, we highlight methods used between teachers to coordinate the delivery, especially with join the course (e.g., courses taught by multiple teachers), methods to coordinate between upper management and head of departments, and between the head of departments and program coordinators.

For this purpose, we conduct a survey, and we managed to receive responses from 122 faculty ( $52.4 \%$ female, $47.6 \%$ male). The total number of respondents represents more than $60 \%$ of all faculty members in the college. Respondents are faculty of applied linguistics department (19.9\%), computer science program (15.4\%), management information systems (12.8\%), computer engineering (10.3\%), accounting (8.9\%), human resource management (6.4\%), marketing (2.5\%), supply chain management (2.5\%), and interior design (2.5\%) (Figure 3).

At this stage, we were more interested to know how much of the curriculum they al-ready covered and how much of the marks (out of 100\%) were collected from assessments. The suspension was during the mid-exams period. We expected most of the courses are covering $50 \%$ of the curriculum since the suspension occurs at the middle of the semester. However, the assessment collected with be less than $50 \%$ because the final exam weight is $40 \%$ of the final grade of each course. In addition, other assessments are in the way between the mid-term and the final exam (e.g., quizzes, projects, assignments), which weight no less than $20 \%$. This will give us an estimation of $40 \%$ collected marks at the time of the suspension. 


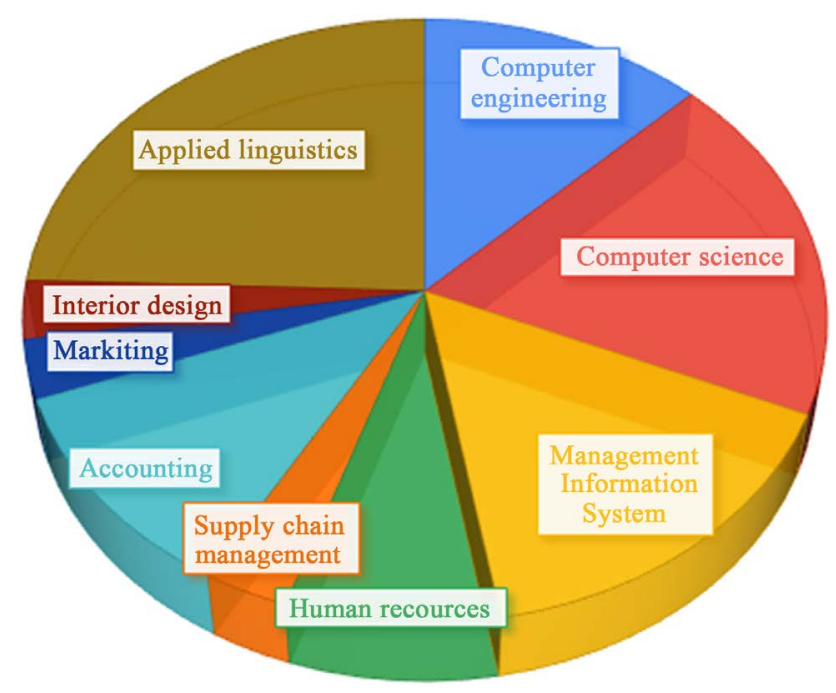

Figure 3. Distribution of the respondents based on program.

\subsection{During the Crisis}

This subsection discusses what happened after the enforcement of the stay-home policy of all students and faculty. This is a type of risk management plan that taken by the college, which includes evaluation of the situation (where we at in terms of the curriculum and grading?), what obstacles we are facing and solutions to mitigate them, and moving forward.

The government of Saudi Arabia suspended students from going to schools or college on the 8th of March 2020. A few days later, the government suspended all government employees from going to work including teachers and faculty. Hospitals' workers, military, police, IT workers were excluded from this decision. Both faculty and students are working remotely. Therefore, coordination between teachers themselves or with the management requires virtual meetings, which add more challenges.

At this stage, we need to analyze what progress was made in each course. The suspension was in the middle of the semester (week 7). Therefore, we expect all courses to be half-way in terms of the syllabus coverage, including assessments. In the survey we made, we were interested to know at what phase of the course they are in. So, we asked how much of the curriculum were covered and what percentage of $65 \%$ of the results were recorded. Most of the courses are divided into 65\% (assignments, projects, mid-terms exam) and 35\% (final exam).

The outcome of Figure 4 shows the part of the syllabus was covered, and the percentage of assessment was made. In terms of the coverage rate, we found that most of the teachers cover between $50 \%$ to $80 \%$ of the syllabus. The highest bar is shown that teachers are between $60 \%$ to $70 \%$ covering the syllabus. This indicates that the remaining of the syllabus is almost between $20 \%$ to $40 \%$, which will be delivered online. The rate of assessment excluding the final exam indicates that most of the teachers managed to conduct $40 \%$ to $60 \%$ of the assessment. This will give us a figure of the overall remaining assessment to be between $50 \%$ to $60 \%$, including $35 \%$ of the final exam. 
We completed two weeks after the beginning of the crisis, which means the evaluation achieves a higher percentage. So, we highlight on progress was made in these two weeks and the approved plan for the remaining four weeks of the semester (Figure 5).

First, the respondents were asked about the tools they used to meet and interact with students. The results are shown in Figure 6, and it shows that most of them (68\%) are using the open-source Learning Management System LMS is an online platform (RCYCI-LMS). The platform is even used before as a support tool form most of the teachers and used to post course materials, homework, quizzes, online assessment, and major announcements to students. However, this tool does not incorporate video conference rooms that allow for real-time meetings with students. Therefore, faculty are using other tools (e.g., zoom and Google hangout). We found that Zoom is heavily used by $65 \%$ of the respondents. Other teachers (20\%) prefer to use Google classrooms due to its simplicity, as it does not contain many tools, as in the LMS, and for those teachers, it serves the basic needs for the course (Figure 6).

In this survey, we needed to get feedback about the effectiveness of the tools. Therefore, the next question was to evaluate the level of e effectiveness these tools are helping them in teaching, as shown in Figure 7. In the Figure, we presented

\section{CURRICULUM COVERAGE}

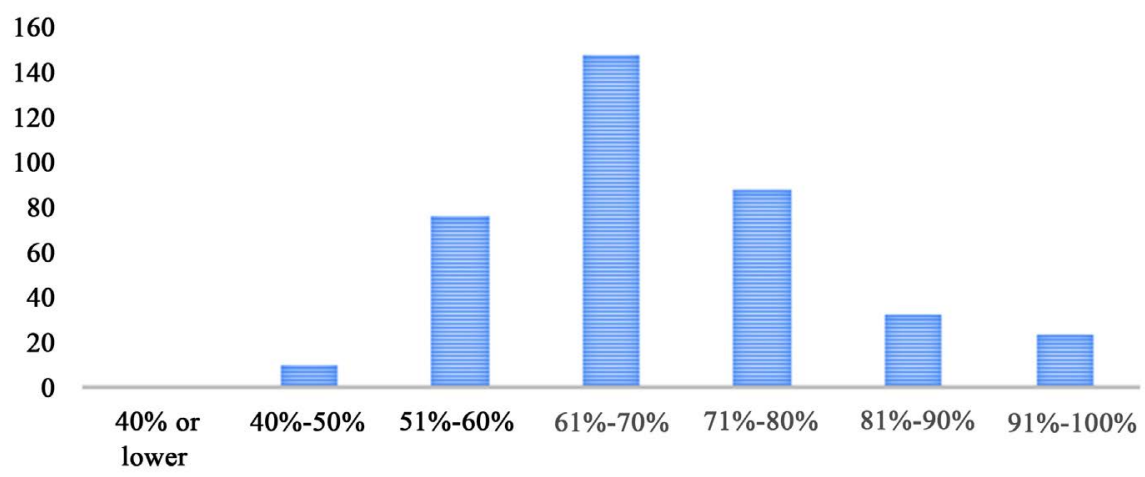

Figure 4. The percentage of corriculum coverage.

AVERAGE OF OBTAINED MARKS

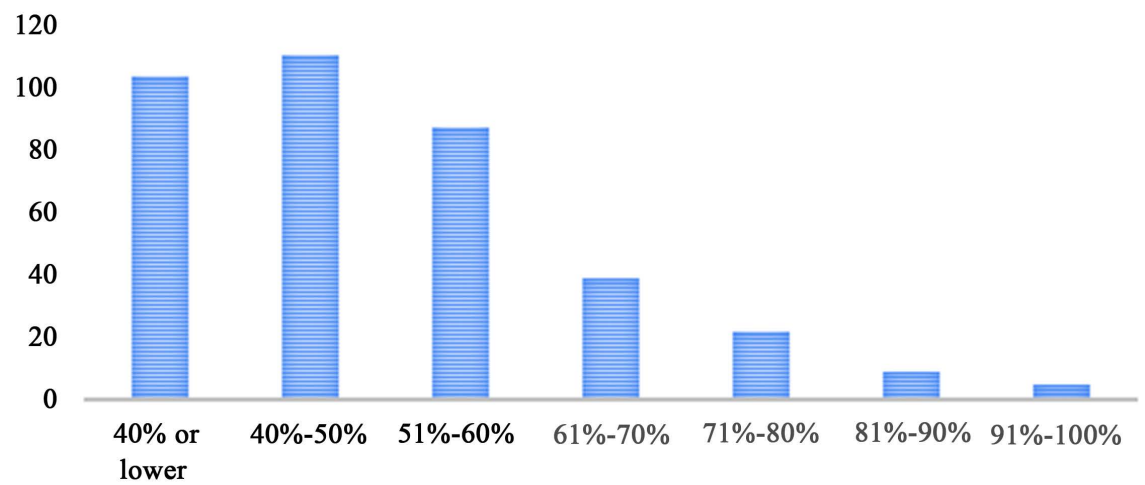

Figure 5. The percentage of obtained marks. 


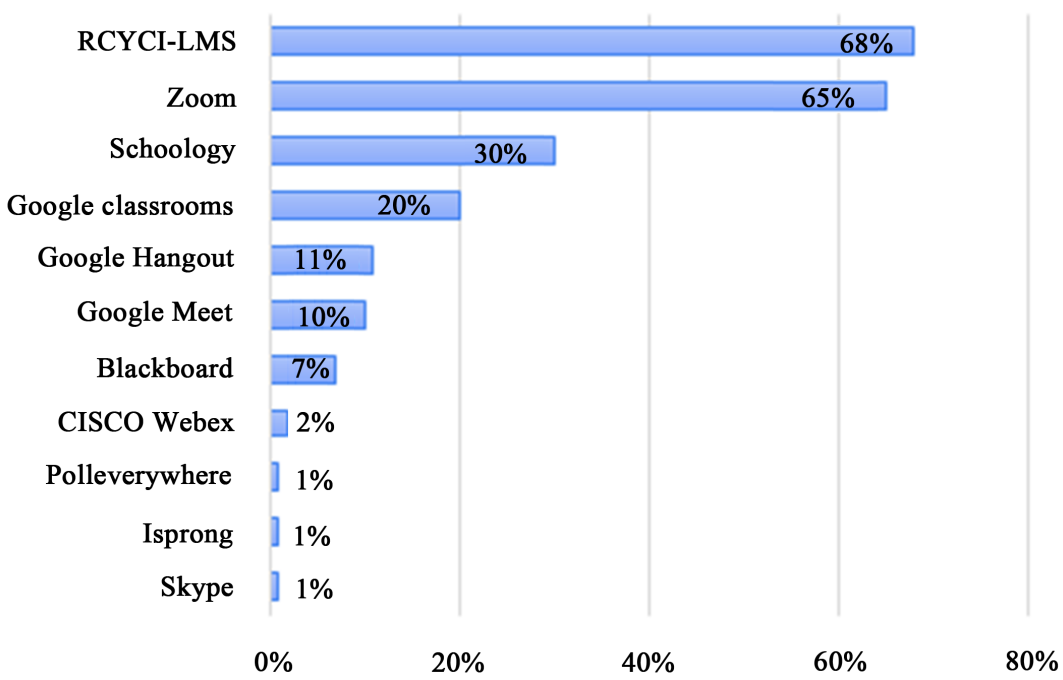

Figure 6. The usage of tools to interact with students during the crisis.

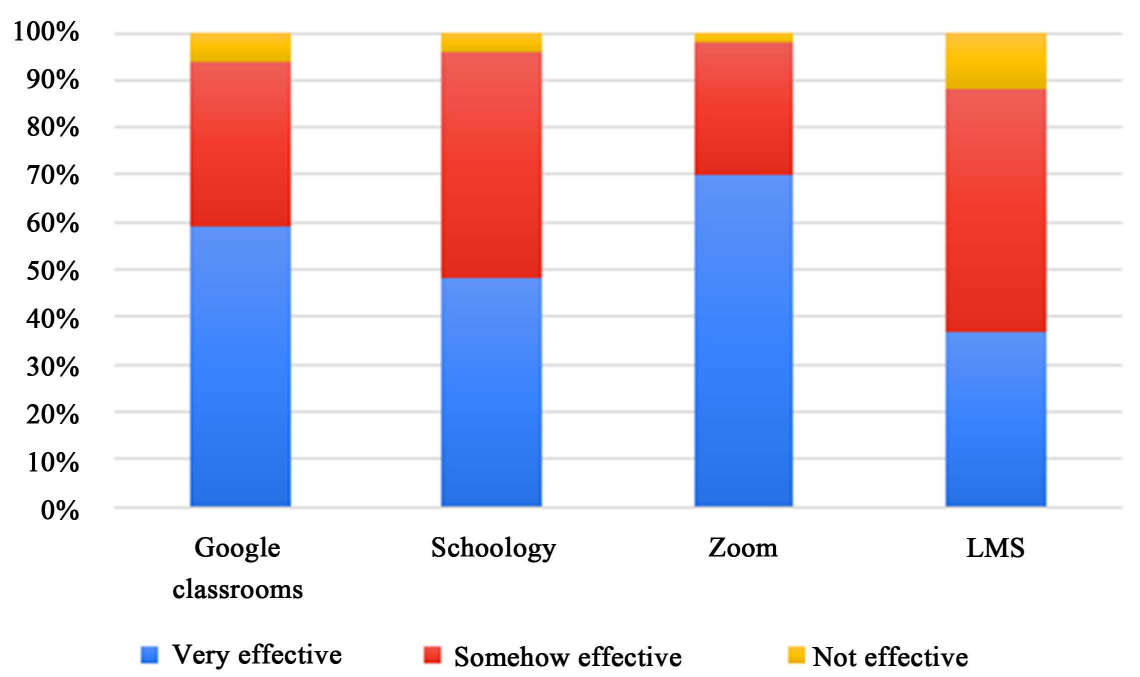

Figure 7. The effectiveness of the tool used to deliver the syllabus.

the effectiveness evaluation for the top tools used by at least $20 \%$ of the respondents. These tools are LMS, Zoom, Schoology, and Google Classroom.

The learning system LMS is not a new tool for most of the teachers. So, their opinion about the effectiveness of the system is likely the same before and after the crisis. Almost $40 \%$ of the respondent believes that the system is very effective, and $55 \%$ believe that the system is somehow effective, and about $5 \%$ believe it is not effective. Based on some feedback from faculty members, they believe the system contains too many tools that are not needed for them. Therefore, they considered it as too complicated for them and contains more features than what they need.

The replacement of the LMS system designed by the development team of the college would be Schoology or Google classrooms. Schoology application is used by $30 \%$ of the faculty and about $45 \%$ of them believe that it is very effective. 
Google Classroom application is used by $20 \%$ of the faculty and $55 \%$ of them believe it is very effective.

With respect to the video conference tool, $65 \%$ of the respondents are using the Zoom video conference. It showed that most of the respondents (75\%) who used the technology are very happy with it, and they believe that it is very effective.

The crisis at this point seems to be extended to the summer and maybe next fall. Therefore, students are likely will not be able to return to school until after summer. As such, the ministry of education suggested to high education institution to replace the final exam by any other method of assessment. Many universities in the kingdom of Saudi Arabia have already announced to their students the news and started to apply the weekly assessment methods, which include reports, presentations, and assignments.

\subsection{Learned Lessons}

The most important lesson we learned from this crisis is that online education is not a luxury option. It is essential to work to improve the online applications and practices of people. People now are more aware and religiously believe in the necessity of online education. So, this is might be the best time to adopt the technology that facilitates online education. The resistance of people will be history as they learned from this crisis how important to work online. It is important to improve IT infrastructure, services related to online education, and increasing throughput of servers to serve many sessions. At the same time, institutions are asked to adopt the state of the art of learning management tools which can help to provide the asynchronous and synchronous format of remote learning.

Teachers need to be more trained on how to use active learning on online teaching, and how to conduct proper assessments. Teachers can incorporate various assessment methods that allow students to achieve course outcomes and enhance students' engagement. Teachers need to be more effective in using online teaching methods, organizing group meetings with their students, and conduct various assessments. This crisis taught all teachers that online teaching is no choice, and they should be using it and learning effective methods.

Students, on the other hand, need to be more engaged in online education. Their engagement increases the benefits of online teaching, So, being responsible in listening to lectures, raising questions, be involved in discussions during lectures, and trying to answer questions will enrich the online education and make it as interesting as face to face education. Due to the lack of time and the overwhelmed amount of coursework given to students, we did not include them in this study. However, we managed to get some of their opinions through their interactions in social media. Their concern was mainly about the final exam and how it can affect their grades. Also, they raised other concerns related to the consistency of the applications used, especially with video conferencing meetings. The last concern was related to the technical capabilities of some teachers in delivering lectures online. Students' attendance was remarkable as shown in Figure 8. 


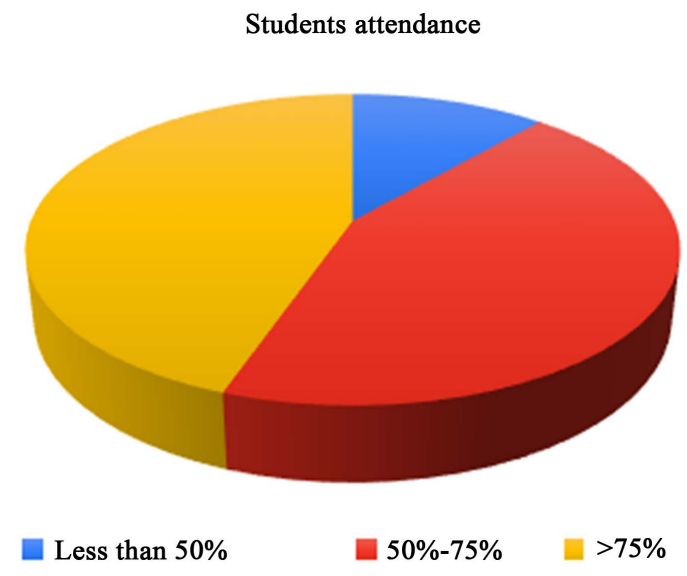

Figure 8. Students attendance on online lectures.

As presented in Figure, $45 \%$ of teachers reported that more than $75 \%$ of students are attending class video meetings. Another $45 \%$ of teachers reported between $50 \%$ to $75 \%$ of students attending classes. Although the attendance chart seems good, many teachers complained about students' engagement.

With respect to the administrative works related to course ling, program review, department councils, and college council were conducted as planned. This also demonstrated that college routine works can be done remotely. Also, other planning workshops were conducted using video conferencing especially with Google hangout software. The reason for using Google hangout software is that a link for a meeting is automatically generated once making the invitation using Google calendar, which makes it easy for everyone rather than sending the link to all members before meetings.

Last, more lessons will be learned if use approaches that involve descriptive analysis as explained in (Alshehri, 2019). We need to handle statistical analysis to compare performances without the crisis and performance with the crisis. The performance involves students' achievements, teachers' performance, and accomplishments of the curriculum. This kind of works can help to understand if the transition affected the quality of regular education or the risk plan helped to achieve what the courses aimed to achieve or more work need to be done to improve the risk plan and find alternatives.

\section{Conclusion}

In conclusion, this paper discussed how a mid-size college in Saudi Arabia handled online education during the COVID19 crisis. It is important to note that the outcomes of this research are not necessarily true in all colleges in Saudi Arabi. It may give an indication of how other colleges did during the crisis, but not necessarily similar to what we found in this paper. The paper also demonstrated through the case study how the crisis was managed in terms of the syllabus delivery and assessments and to be able to complete the second half of the semester (Spring 2020). The paper also highlighted some challenges associated with these transitions and highlighted some lessons learned from this crisis. 
Future work may involve analysis of different experiences of colleges across the globe and how they handled the crisis. This may enrich the overall experience of managing this crisis in the future. Also, we may need to explore reviewing policies and education risk plans to see how they can be changed to cover such risks. We may need to explore methods incorporate with online teaching to enhance students' engagement. We need more empirical studies to explore if the course outcomes have no significant difference when students are taught online versus students had regular education. The study should cover various courses from different disciplines.

\section{Acknowledgements}

We would like to express our thanks to the Royal Commission at Yanbu for allowing us to disclose the data collected from Yanbu University College and use it for this research. Our gratitude is due to the director general of the Education Division, Dr. Maher Alghanem, for his continuous support.

\section{Conflicts of Interest}

The authors declare no conflicts of interest regarding the publication of this paper.

\section{References}

Ali, M. G., Ahmad, M. O., \& Husain, S. N. (2020). Spread of Corona Virus Disease (Covid-19) from an Outbreak to Pandemic in the Year 2020. Asian Journal of Research in Infectious Diseases, 3, 37-51. https://doi.org/10.9734/ajrid/2020/v3i430135

Al-Khalifa, H. S. (2009). The State of Distance Education in Saudi Arabia. eLearn, 10, Article No. 9. https://doi.org/10.1145/1626550.1642193

Alshehri, Y. A. (2019). Applying Explanatory Analysis in Education Using Different Regression Methods. In Proceedings of the 2019 4th International Conference on Information and Education Innovations (pp. 109-115). New York: Association for Computing Machinery. https://doi.org/10.1145/3345094.3345111

Anderson, T. (2008). The Theory and Practice of Online Learning. Athabasca: Athabasca University Press.

Archambault, L., \& Borup, J. (2020). Coming Together as a Research Community to Support Educators and Students in k-12 Online and Emergency Remote Settings. Journal of Online Learning Research, 6, 1-3.

Bourne, J., Harris, D., \& Mayadas, F. (2005). Online Engineering Education: Learning Anywhere, Anytime. Journal of Engineering Education, 94, 131-146. https://doi.org/10.1002/j.2168-9830.2005.tb00834.x

Bozkurt, A., \& Sharma, R. C. (2020). Emergency Remote Teaching in a Time of Global Crisis Due to Coronavirus Pandemic. Asian Journal of Distance Education, 15, 1-6.

Chen, Q., Quan, B., Li, X., Gao, G., Zheng, W., Zhang, J., Zhang, Z., Liu, C., Li, L., Wang, C. et al. (2020). A Report of Clinical Diagnosis and Treatment of 9 Cases of Coronavirus Disease 2019. Journal of Medical Virology, 92, 683-687.

https://doi.org/10.1002/jmv.25755

Chen, X., \& Koricich, A. (2014). Reaching Out to Remote Places: A Discussion of Technology and the Future of Distance Education in Rural America. In E-Learn: World Conference on 
eLearning in Corporate, Government, Healthcare, and Higher Education (pp. 370-376). San Diego, CA: Association for the Advancement of Computing in Education (AACE).

Hasan, S., \& Hossain, M. M. (2020). Analysis of Covid-19 m Protein for Possible Clues Regarding Virion Stability, Longevity and Spreading. https://doi.org/10.31219/osf.io/e7jkc

Hodges, C., Moore, S., Lockee, B., Trust, T., \& Bond, A. (2020). The Difference between Emergency Remote Teaching and Online Learning. EDUCAUSE Review. https://er.educause.edu/articles/2020/3/the-difference-between-emergency-remote-teac hing-and-online-learning

McCartin, L. (2020). Prioritizing Curriculum during Emergency Remote Teaching.

Nash, J. A. (2015). Future of Online Education in Crisis: A Call to Action. Turkish Online Journal of Educational Technology, 14, 80-88.

Rajab, K. D. (2018). The Effectiveness and Potential of e-Learning in War Zones: An Empirical Comparison of Face-to-Face and Online Education in Saudi Arabia. IEEE Access, 6, 6783-6794. https://doi.org/10.1109/ACCESS.2018.2800164

Schrading, W. A., Pigott, D., \& Thompson, L. (2020). Virtual Remote Attending Supervision in an Academic Emergency Department during the Covid-19 Pandemic. AEM Education and Training. https://doi.org/10.1002/aet2.10460

Smith, E. E. (2020). 3 Things to Consider When Designing Remote Teaching.

Walabe, E. (2020). E-Learning Delivery in Saudi Arabian Universities. PhD Thesis, Ottawa: University of Ottawa.

WHO World Health Organization (2020). Coronavirus Disease 2019 (COVID-19): Situation Report 85. 